\title{
"Pusher-To-Retriever Repurposing" as a Novel Endoscopic Bailout for Proximal Biliary Stent Migration
}

\author{
Vincent Zimmer ${ }^{a}$ b Siegfried Exner ${ }^{a}$ \\ a Department of Medicine, Marienhausklinik St. Josef Kohlhof, Neunkirchen, Germany; \\ ${ }^{b}$ Department of Medicine II, Saarland University Medical Center, Saarland University, Homburg, Germany
}

Keywords

Endoscopic retrograde cholangiopancreatography · Stent migration · Endoscopic extraction · Endoscopy

\section{"Pusher-to-retriever repurposing" como uma nova solução endoscópica para a migração proximal de prótese biliar}

\section{Palavras Chave}

Colangiopancreatografia retrógrada endoscópica ·

Migração prótese · Extração endoscópica · Endoscopia

A 62-year-old patient presented for endoscopic retrograde cholangiopancreatography (ERCP) due to bile leakage with incipient biliary peritonitis after laparoscopic cholecystectomy. After biliary access, cholangiography confirmed cystic duct leakage, and biliary stenting using a 10-Fr (7 cm; Optimed, Ettlingen, Germany) double pigtail was performed after medium-size papilloto-

\section{KARGER}

(C) 2019 Sociedade Portuguesa de Gastrenterologia Published by S. Karger AG, Basel

Karcer

Open access

This article is licensed under the Creative Commons AttributionNonCommercial-NoDerivatives 4.0 International License (CC BYNC-ND) (http://www.karger.com/Services/OpenAccessLicense) Usage and distribution for commercial purposes as well as any distribution of modified material requires written permission. my. However, given a, in retrospect, too short stent length, the distal end of the stent became wedged into the pre-papillary common bile duct after release. Various attempts to extract the stent by baskets and/or foreign body forceps failed due to lack of maneuverability in this narrow operative field with a decision made to terminate the first ERCP session by transpapillary implantation of a longer 11-cm stent into the right hepatic system (Fig. 1a, note cystic duct leakage with surgical drainage and migrated stent in the left hepatic duct). In another ERCP session 2 days later and after successful stent re-cannulation (Fig. 1b, 2a), an over-the-wire snare approach likewise failed, such that we resorted to a "small-for-size" 7-Fr stent pusher (Optimed), being advanced deeply until dynamic cholangiography confirmed a tight connection to the variably deformed stent (Fig. $1 c, 2 b$, note the radiolucent nature of the pusher). Next, the stent was extracted by pulling back the pusher (Fig. 1d, 2c). The intimate association of the "pusher-stent complex" is additionally illustrated ex vivo in Figure 2d. Finally, another sufficiently long stent with the same specifications as before (10-Fr, 11-cm; see Fig. 1a) was re-inserted, and 

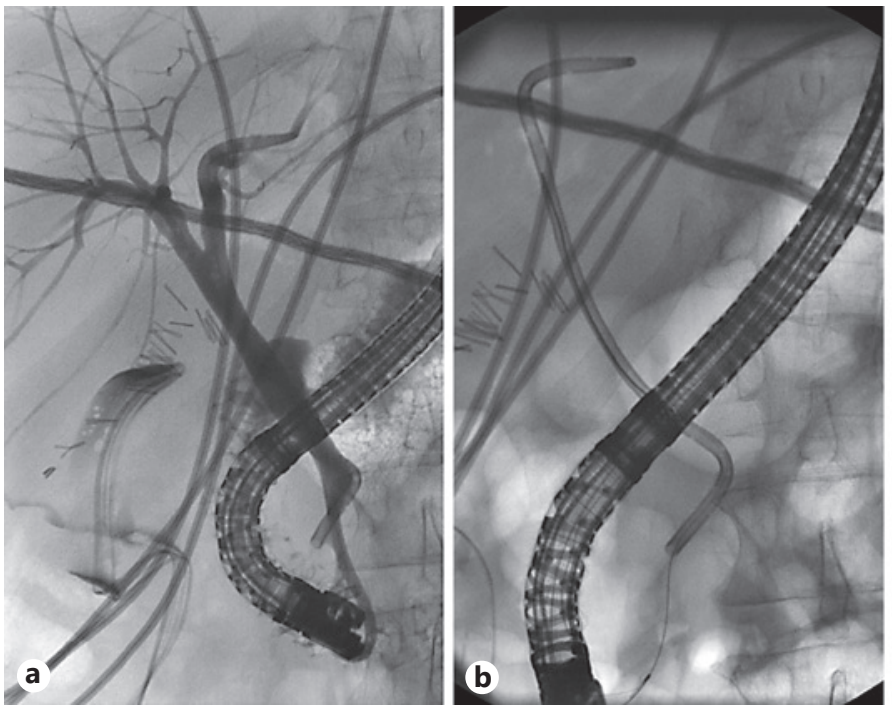

Fig. 1. Fluoroscopic demonstration of the "pusher-to-retriever repurposing" approach. a Proximal migration of biliary plastic stent with insertion of another stent (right hepatic) to ensure transpapillary drainage in the first ERCP session. Note cystic duct leakage alongside a percutaneous surgical drain. b Successful cannulation
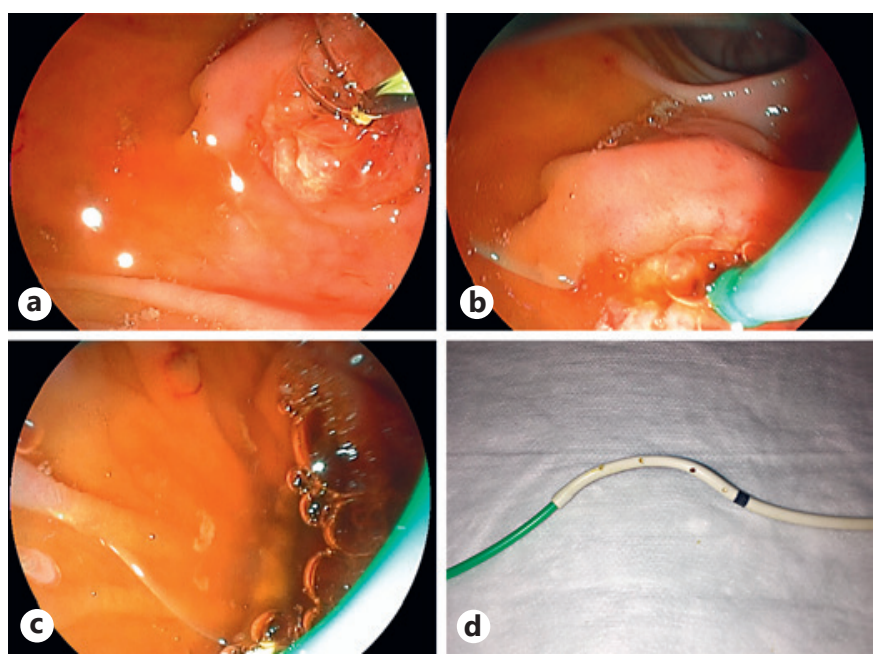

Fig. 2. Endoscopic demonstration of the "pusher-to-retriever repurposing" approach. a Migrated stent re-cannulation by a 0.035 in guidewire. b The "small-for-size" stent pusher (7-Fr) engaging the migrated stent (10-Fr). c Successful transpapillary extraction of the stent. $\mathbf{d}$ Ex vivo illustration of the "pusher-stent complex."
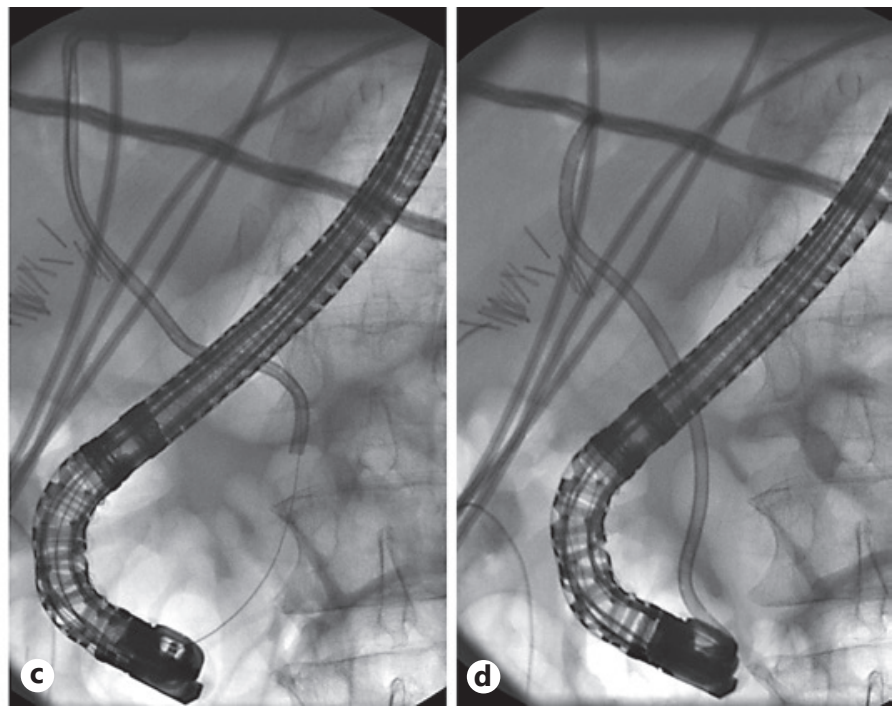

of the 10-Fr biliary double pigtail stent wedged in the prepapillary segment by a 0.035 -in guidewire. c The (radiolucent) 7 -Fr pusher firmly engaging the migrated stent with visible deformation. d Transpapillary stent extraction by pulling the stent pusher.

re-ERCP scheduled 4 weeks later, according to standard proceedings in our center, with documentation of leakage closure.

There are myriad techniques available for proximal biliary stent migration both over-the-wire or freehand [1]. Here, a novel endoscopic bailout is introduced as "pusher-to-retriever repurposing" reminiscent of the Soehendra stent retriever approach, albeit associated with less costs and probably more widely available in endoscopy services.

\section{Statement of Ethics}

Patient consent has been obtained.

\section{Disclosure Statement}

The authors have no conflicts of interest to report.

Reference

1 Chaurasia OP, Rauws EA, Fockens P, Huibregtse K. Endoscopic techniques for retrieval of proximally migrated biliary stents: the Amsterdam experience. Gastrointest Endosc. 1999 Dec;50(6):780-5. 